\title{
Unterschätzte Gefahr bei Typ-2-Diabetes
}

- Das Risiko von Hypoglykämien wird bei Patienten mit Typ-2-Diabetes vor allem bei Therapie mit Sulfonylharnstoffen und Insulin unterschätzt. Schwere Hypoglykämien sind jedoch mit einer höheren Mortalität und kardiovaskulären Letalität assoziiert.

Hypoglykämien sind für den Patienten extrem unangenehm, betonte Prof. Dr. Martin Pfohl, Duisburg. Als „leicht“ wird eine Hypoglykämie dann bezeichnet, wenn noch eine Selbsttherapie durch den Patienten möglich ist. Die schwere Form ist durch zentralnervöse Symptome und Bewusstlosigkeit gekennzeichnet. Nach der Definition der Deutschen Diabetesgesellschaft liegt eine Hypoglykämie vor, wenn der Blutzuckerspiegel unter $50 \mathrm{mg} /$ dl (<2,8 mmol/l) sinkt. Dieser Grenzwert ist jedoch laut Pfohl viel zu niedrig. Viele Patienten könnten bei einem so niedrigen Blutzuckerspiegel gar nicht mehr reagieren. Pfohl empfiehlt deshalb, sich an den Definitionen der American Diabetes Association zu orientieren: Danach besteht eine Hypoglykämie schon bei einem Blutzuckerspiegel < $70 \mathrm{mg} / \mathrm{dl}(<3,9 \mathrm{mmol} / \mathrm{l})$.
Eine Hypoglykämie gefährdet den Patienten nicht nur wegen eines erhöhten Unfallrisikos, sondern auch durch klinische Folgen. So hatten in der ACCORDStudie Patienten mit schweren Hypoglykämien unabhängig vom Behandlungsarm eine höhere Sterblichkeit (Tab. 1). Die Ursachen hierfür sind noch unklar. Untersuchungen an Herzinfarktpatienten belegen jedoch, dass Hypoglykämien in der Akutphase ebenfalls mit einer erhöhten Letalität und Reinfarktrate einhergehen.

\section{Substanzen mit niedrigem} Hypoglykämierisiko bevorzugen „In Deutschland leisten wir uns den Luxus, dass wir - abgesehen von Metformin - in der Diabetestherapie vor allem auf zwei Substanzen setzen, die ein erhöhtes Hypoglykämierisiko haben, nämlich Glibenclamid und Insulin“, sagte Pfohl. Bei den etwa $5 \%$ Typ-2-Diabetikern, die durch Hypoglykämien gefährdet sind, sollte man nicht bei diesen Substanzen bleiben. Für eine normnahe Blutzuckereinstellung sollten in Kombination mit Metformin bevorzugt Substanzen mit niedrigem Hypoglykämierisiko eingesetzt werden wie z. B. Rosiglitazon (Fixkombination Avandamet ${ }^{\circledR}$ ). Wie Studien zeigen, lässt sich damit das Hypoglykämierisiko um bis zu $80 \%$ senken.

- Dr. Susanne Heinzl

Quelle: Pressegespräch, München, 6. August 2009 (Veranstalter: GlaxoSmithKline $\mathrm{GmbH}$ )

\section{Tabelle 1}

Hypoglykämie und Mortalität (ACCORD-Studie)

\begin{tabular}{|c|c|c|c|}
\hline & \multicolumn{3}{|c|}{ Mortalität pro Jahr } \\
\hline & Gesamt & $\begin{array}{l}\text { Patienten ohne } \\
\text { Hypoglykämien }\end{array}$ & $\begin{array}{l}\text { Patienten mit } \\
\text { Hypoglykämien }\end{array}$ \\
\hline $\begin{array}{l}\text { Intensiv } \\
\text { behandelter Arm }(n=5128)\end{array}$ & $1,4 \%$ & $1,3 \%$ & $2,8 \%$ \\
\hline Standardarm $(n=5123)$ & $1,1 \%$ & $1,1 \%$ & $4,9 \%$ \\
\hline
\end{tabular}

\section{Studien zum Wirkpotenzial von Langzeitnitrat}

\section{Mit CAESAR und CLEOPATRA auf zu neuen Ufern}

- Pentaerithrityltetranitrat (PETN, Pentalong ${ }^{\circledR}$ ), mit Abstand das meistverordnete Langzeitnitrat in Deutschland, sorgt mit neuen klinischen Studien für Aufsehen. In den letzten 15 Jahren hatten vor allem Grundlagenforscher mit ihren Arbeiten zur Nitratwirkung von sich reden gemacht. Sie konnten zeigen, dass sich PETN von allen anderen therapeutischen Nitraten unterscheidet. Vor allem: Die antianginöse Dauertherapie mit PETN provoziert keine Toleranzentwicklung. Die Sonderstellung des PETN ist seit Neuestem auch auf genetischer Ebene nachgewiesen. So induzieren Nitroglyzerin (NTG) und PETN am Rattenherzen eine völlig unterschiedliche Genregulation. Neueste
Befunde legen nahe, dass unter NTG auch kardiotoxische, unter PETN vor allem kardioprotektive Gene aktiv werden.

\section{Zusatztherapie bei Lungenhochdruck?}

Um das Wirkpotenzial von PETN besser einschätzen zu können, sind zwei weitere klinische Studien mit randomisiertem und placebokontrolliertem Design geplant: CAESAR und CLEOPATRA. Mit CAESAR hofft man herauszufinden, ob PETN die Therapie des Lungenhochdrucks verbessern kann. Eine Pilotstudie an der Universität Köln vor einigen Jahren hat vielversprechende Hinweise erbracht. Der Direktor des Herzzentrums Köln, Prof. Dr. Erland
Erdmann, wird als Studienleiter dieses Thema mit CAESAR weiterverfolgen.

CLEOPATRA will wissen, in welchem Ausmaß sich die Belastungsfähigkeit von Patienten mit stabiler Angina pectoris durch PETN steigern lässt. Studienleiter Prof. Thomas Münzel, Mainz, erwartet sich nicht nur einen überzeugenden Wirkungsnachweis, sondern auch einen soliden Beleg für die Sicherheit und Verträglichkeit einer zwölfwöchigen Behandlung mit zweimal täglich 80 mg PETN im Vergleich zu Placebo.

\footnotetext{
- Dr. med. Jochen Aumiller Quelle: 16. Expertentreffen PETN, Magdeburg am 17. Oktober 2009 (Veranstalter: Actavis Deutschland)
} 